\title{
Effect of Pre-annealing on Sintering of Stainless Steel Fiber Felt
}

\author{
H.P. TANG $\odot{ }^{1,3,4}$ J. MA, ${ }^{1}$ J.Z. WANG ${ }^{1}$ and C.L. $\mathrm{LI}^{1,2}$ \\ 1.-State Key Laboratory of Porous Metal Materials, Northwest Institute for Nonferrous Metal \\ Research, Xi'an 710016, China. 2.-School of Materials and Metallurgy, Northeastern University, \\ Shenyang 110819, China. 3.—e-mail: thpfys@126.com. 4.-e-mail: hptang@c-nin.com
}

\begin{abstract}
Stainless steel fiber felt is a class of unique porous metal materials. This study investigates the effect of pre-annealing on the sintering of stainless steel fiber felt through quantitative characterization of sintered joints based on synchrotron radiation experiments. The sintered joint size was found to follow a marked normal distribution in fiber felt samples sintered with and without pre-annealing. However, pre-annealing prior to sintering led to a significant reduction in the total number of sintered joints as well as a reduction in the percentage of large sintered joints. Consequently, fiber felt samples sintered with pre-annealing achieved less than half the tensile strength of those sintered without pre-annealing. Delamination through fracture of sintered joints was pronounced in fiber felt samples sintered with pre-annealing, while failure occurred mainly through fracture of individual fibers in those sintered without pre-annealing. It was concluded that sintering without pre-annealing is necessary for the fabrication of high-strength fiber felt products and the reasons are briefly discussed.
\end{abstract}

\section{INTRODUCTION}

Stainless steel fiber felt is a class of unique porous metal materials which have found important industry applications, including high-volume filtration or separation, sound absorption or noise control, heat transfer, energy absorption, carriers of catalytic converters, and surface combustion. ${ }^{1-4}$ Their production consists of three basic steps: (1) long bundledrawn fibers are cut into short fibers with a lengthto-diameter ratio of $\sim 1000,(2)$ preforms are made of the short fibers through an air-laid process and compacted to required porosity, and (3) compacted preforms are sintered in a special atmosphere. ${ }^{5}$ Sintering is a key step in the production of stainless steel fiber felt products. ${ }^{5,6}$ Owing to their high dislocation density, as-received bundle-drawn stainless steel fibers exhibit both high strength (900$1700 \mathrm{MPa})$ and high elasticity ( 130 GPa), which can be problematic in the fabrication of thick fiber felt products required for noise control and energy absorption. For example, to make a $10-\mathrm{mm}$-thick fiber felt product, the thickness of the air-laid fiber felt preform often reaches $500 \mathrm{~mm}$. The high elasticity and strength make the subsequent compaction process difficult to manage. Annealing is an effective method to reduce the dislocation density in stainless steel fibers for more flexible fabrication of thick fiber felt products (the elastic modulus of stainless steel fiber annealed at $1000^{\circ} \mathrm{C}$ for $10 \mathrm{~min}$ decreases to about $40 \mathrm{GPa}$ from $130 \mathrm{GPa}$ before annealing). Thus, the pre-annealing process can reduce the height of the fiber sheet and enable the felt preform to be easily compacted to the designed height, which is preferred for producing thick fiber felt products. To the authors' best knowledge, no previous study has been reported on the influence of pre-annealing on the sintering of stainless steel fiber felt. This study is carried out to fill this knowledge gap for the fabrication of thick stainless steel fiber felt products.

\section{EXPERIMENTAL PROCEDURE}

\section{Materials and Preparation of Samples}

Bundle-drawn long 316L stainless steel fibers $28 \mu \mathrm{m}$ in diameter were cut into 28 -mm-long short fibers for fabrication of fiber felts. Each air-laid fiber sheet was about $5 \mathrm{~mm}$ thick. Fiber felt preforms were prepared by superimposing 70 sheets to achieve the required sample dimensions $(140 \mathrm{~mm}$ square and $350 \mathrm{~mm}$ high). Three such samples were uniaxially pressed to the height of $10 \mathrm{~mm}(80 \%$ of porosity) at room temperature, and three samples 
were annealed at $850^{\circ} \mathrm{C}$ for $30 \mathrm{~min}$ in a vacuum of $10^{-4} \mathrm{~Pa}$, which reduced the height from $350 \mathrm{~mm}$ to about $90 \mathrm{~mm}$, followed by uniaxial compaction also to the height of $10 \mathrm{~mm}$. Finally, all six samples were sintered at $1000^{\circ} \mathrm{C}$ for $10 \mathrm{~min}$ in a vac- uum of $10^{-4} \mathrm{~Pa}$ (heating rate: $10^{\circ} \mathrm{C} / \mathrm{min}$ ) and furnace-cooled afterwards. The isothermal sintering condition $\left(1000^{\circ} \mathrm{C}, 10 \mathrm{~min}\right)$ was selected based on previous studies. ${ }^{5,7}$
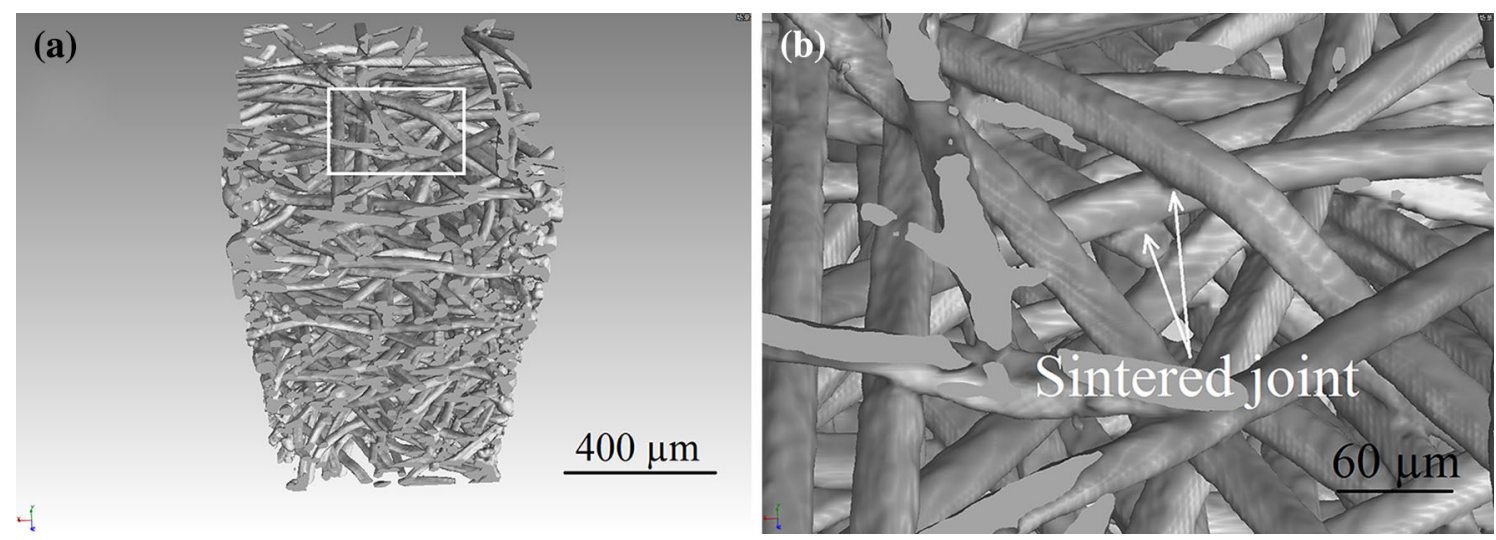

Fig. 1. (a) 3D image of a sintered fiber felt sample reconstructed from 2048 slices. (b) A closer inspection of the area marked out in (a) showing two sintered joints and the angle between fibers at each joint.
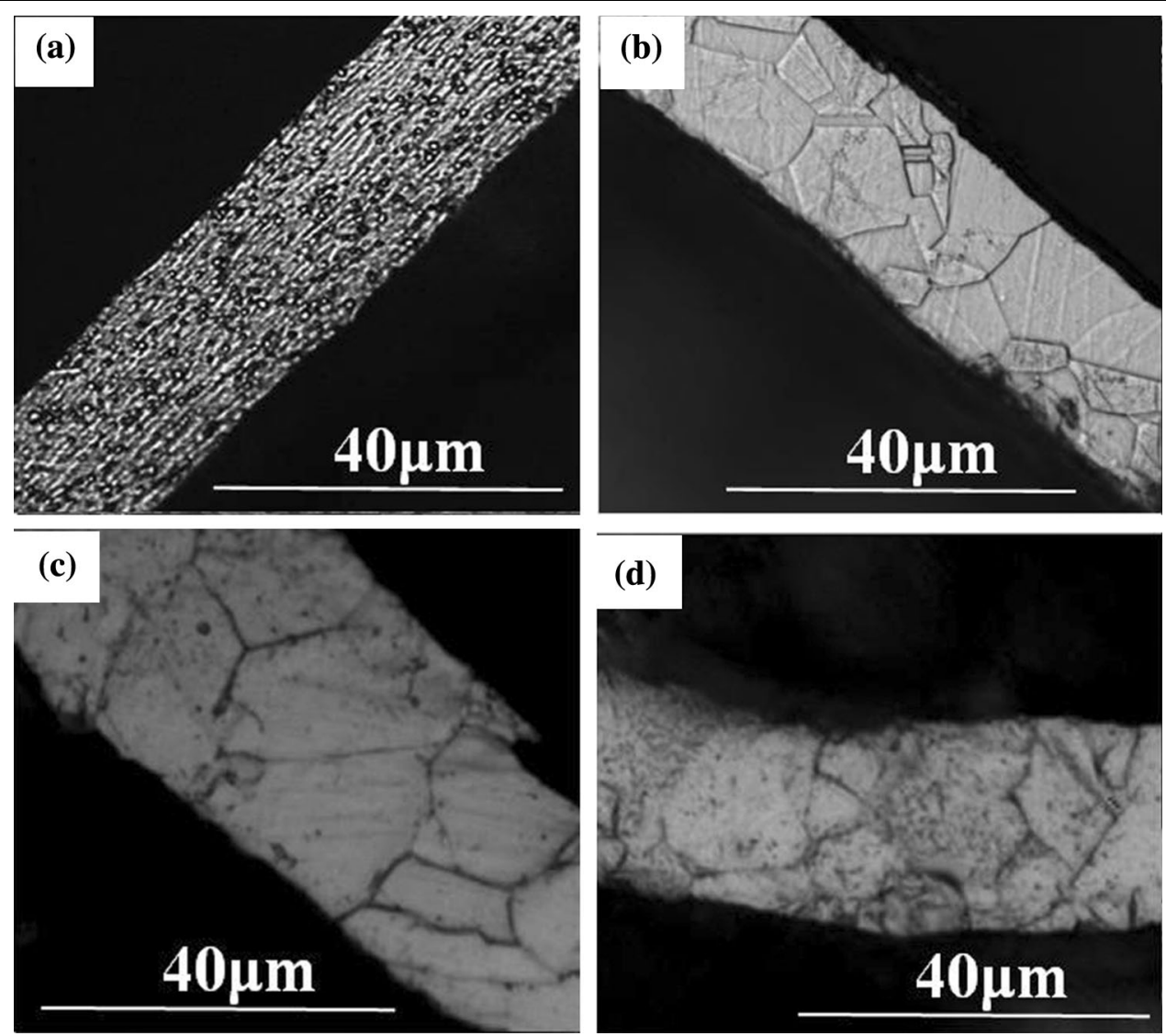

Fig. 2. Microstructure of stainless steel fibers in different conditions. (a) As-drawn, $28 \mu \mathrm{m}$ in diameter. (b) Annealed at $850^{\circ} \mathrm{C}$ for $30 \mathrm{~min}$ (c) Sintered at $1000^{\circ} \mathrm{C}$ for $10 \mathrm{~min}$. (d) Pre-annealed at $850^{\circ} \mathrm{C}$ for $30 \mathrm{~min}$ and then sintered at $1000^{\circ} \mathrm{C}$ for $10 \mathrm{~min}$. 

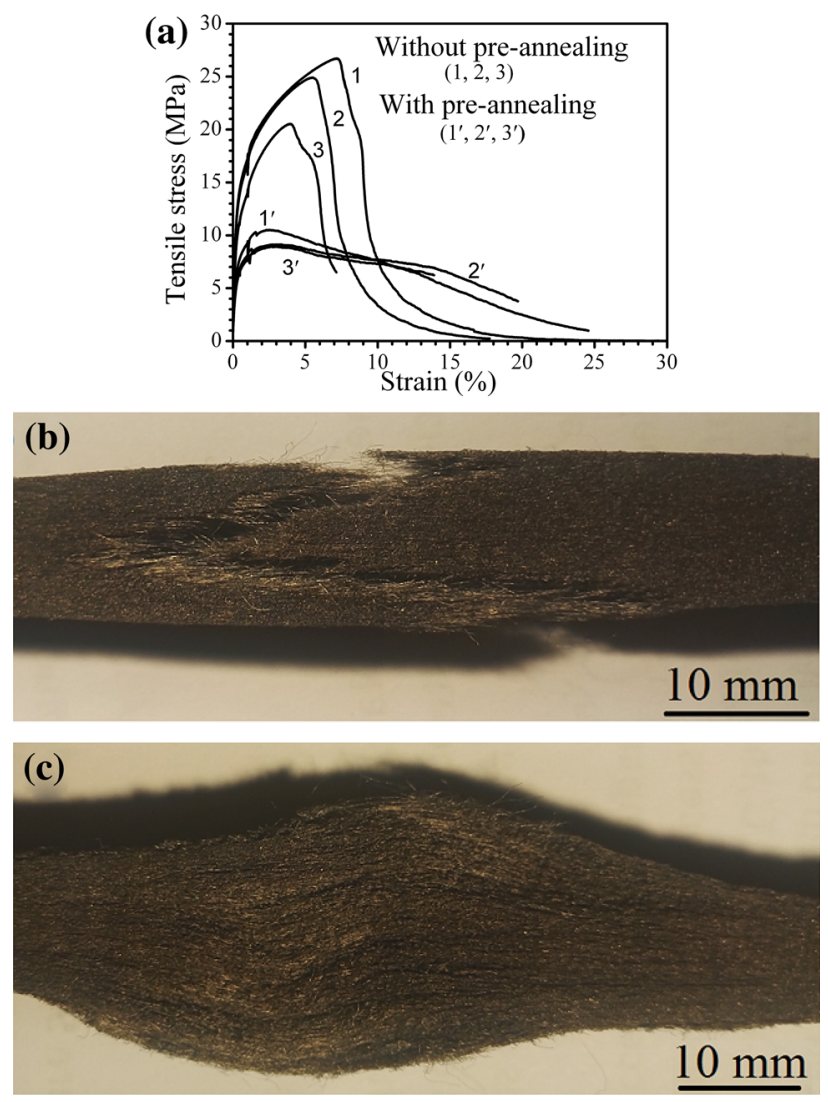

Fig. 3. (a) Tensile stress-strain curves of fiber felt samples sintered with and without pre-annealing $\left(850^{\circ} \mathrm{C}\right.$ for $\left.10 \mathrm{~min}\right)$. Sintered fiber felt tensile samples after tensile testing without (b) and with (c) preannealing.

Tensile testing was performed on an INSTRON $30 \mathrm{kN}$ universal testing machine at room temperature. The tensile samples had the dimensions of $10 \mathrm{~mm} \times 10 \mathrm{~mm} \times 130 \mathrm{~mm}$ (length) with a gauge section of $50 \mathrm{~mm}$. Three samples were tested for each condition. The loading was applied to achieve a constant reduction rate of $1.5 \mathrm{~mm} / \mathrm{min}$ in sample length.

\section{Characterization of Sintered Joints via Syn- chrotron Radiation Experiments}

As-sintered fiber felt samples were analyzed using an x-ray Imaging Beam Line on the BL13W1 Beam Line Station at Shanghai Synchrotron Radiation Facility (special resolution: $0.65 \mu \mathrm{m})$. Detailed experimental procedures and characterization methods have been reported in Refs. 5-7. Briefly, cylindrical fiber felt samples of $\varnothing 1.2 \mathrm{~mm} \times 2.0 \mathrm{~mm}$ were used for synchrotron radiation study. The number and size of the sintered joints together with the angle between the fibers at each sintered joint were measured from threedimensional (3D) digital samples (Fig. 1), each of which was reconstructed from 2048 slices obtained from each real sample. Optical microscopy and scanning electron microscopy were used to study grain structures and fracture surfaces.

\section{RESULTS AND DISCUSSION}

As-drawn stainless steel fibers are composed of ultrafine elongated grains along their axial direction (Fig. 2a). Annealing at $850^{\circ} \mathrm{C}$ for $30 \mathrm{~min}$ led to non-uniform coarse grains in each fiber due to recrystallization (Fig. 2b). Sintering at $1000^{\circ} \mathrm{C}$ for $10 \mathrm{~min}$ without pre-annealing produced similar grain structures (Fig. 2c), as did pre-annealing $\left(850^{\circ} \mathrm{C}\right.$ for $\left.30 \mathrm{~min}\right)$ plus sintering $\left(1000^{\circ} \mathrm{C}\right.$ for $10 \mathrm{~min}$ ) (Fig. 2d). Pre-annealing at $850^{\circ} \mathrm{C}$ thus exerted a negligible influence on the final grain structures of the fiber felt that was subsequently sintered at $1000^{\circ} \mathrm{C}$ for $10 \mathrm{~min}$ due to the higher isothermal holding temperature. However, pre-annealing made the fiber felt preforms much more flexible than prior to annealing. As mentioned in "Materials and Preparation of Samples" section, pre-annealing at $850^{\circ} \mathrm{C}$ reduced the height of the fibre felt preform from $350 \mathrm{~mm}$ to about $90 \mathrm{~mm}$, which is desired for the manufacture of fiber felt products.

Figure $3 \mathrm{a}$ shows the tensile stress-strain curves of fiber felt samples sintered with and without preannealing. Fiber felt samples sintered with preannealing unexpectedly achieved less than half of the tensile strength of those sintered without preannealing. The failure mode is also clearly different for the tensile stress-strain curves. The tensile stress applied to samples sintered without preannealing dropped abruptly to nearly zero after reaching the maximum compared to a progressive decline in samples sintered with pre-annealing. Since the grain structures are similar after sintering with or without pre-annealing (Fig. 2), the distinctly different mechanical responses observed had arisen from other reasons.

The macro-fracture characteristics of the fiber felt tensile samples are displayed in Fig. 3b and c. Fiber felt samples sintered without pre-annealing all fractured during tensile testing, as shown in Fig. 3b. No interlayer delamination was observed, indicating that the sintered joints in these samples provided sufficient layer-to-layer joining. In contrast, fiber felt samples sintered with pre-annealing all showed noticeable interlayer delamination (Fig. 3c), indicative of weak joining between fiber layers. A closer inspection of the fractured tensile samples further confirmed these observations. Fracture of individual fibers occurred predominantly in fiber felt samples sintered without pre-annealing (Fig. 4a), where fractured fibers exhibited clear necking (Fig. 4b), consistent with the $4-8 \%$ of tensile strain obtained (Fig. 3a). In contrast, few fractured fibers were observed in fiber felt samples sintered with pre-annealing (Fig. 4c), and the fibers 

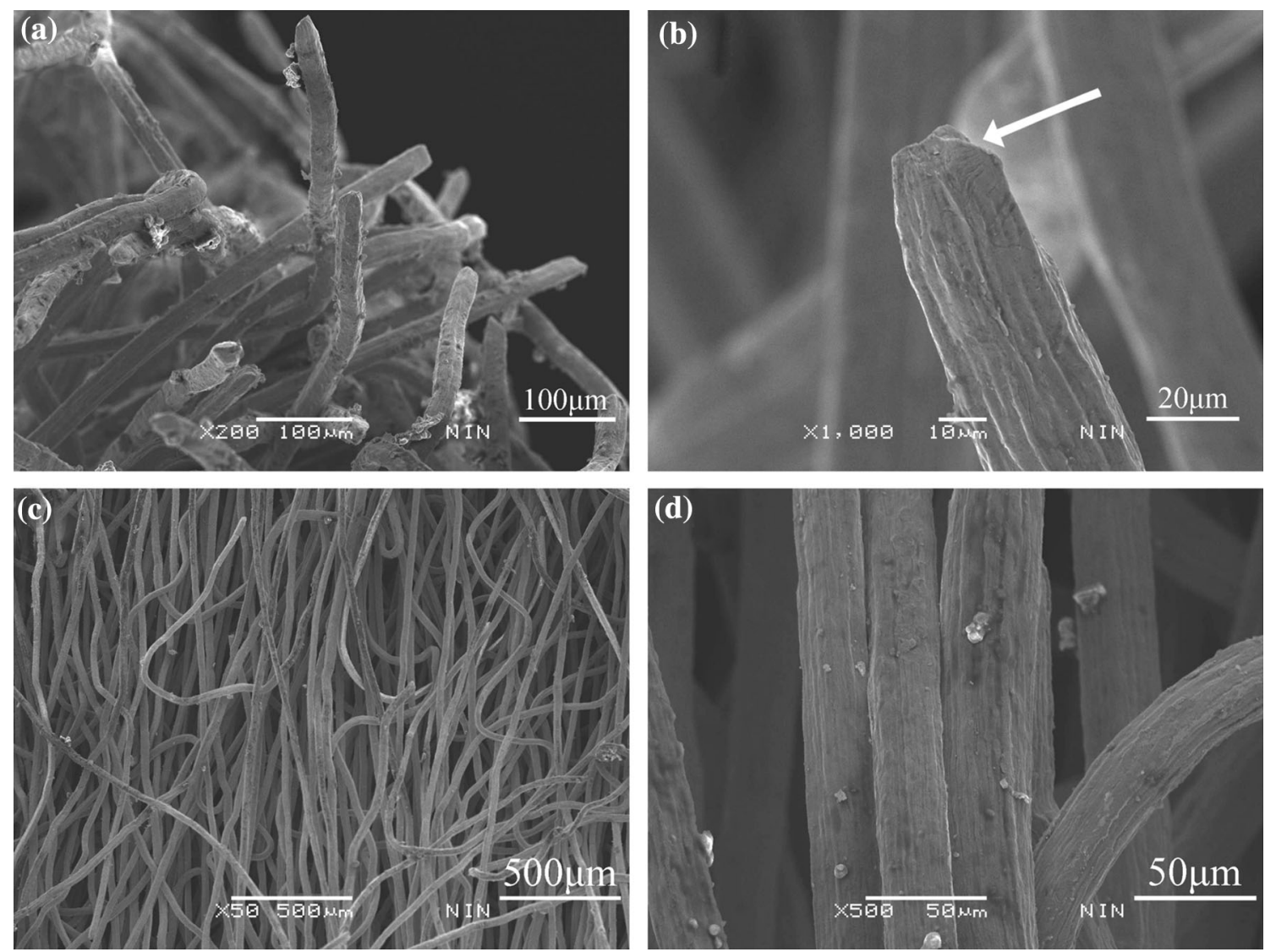

Fig. 4. (a) Fracture surface of a tensile sample sintered without pre-annealing. (b) A fractured fiber from (a). (c) Delaminated region of a tensile sample sintered with pre-annealing. (d) Fibers from (c) showing limited sintering between fibers.

appeared to be loose-packed together with limited sintering (Fig. $4 \mathrm{~d}$ ), in line with the significant delamination shown in Fig. 3c.

The number and size of sintered joints are known to play a critical role in determining the mechanical properties of sintered fiber felt. ${ }^{8}$ Figure 5 shows the number and size of sintered joints obtained from samples sintered with and without pre-annealing based on synchrotron radiation experiments. Samples sintered without pre-annealing attained $40 \%$ more sintered joints than those sintered with preannealing (314 versus 221). In addition, sintered joint size showed no clear dependence on the fiberfiber angle at the joint in either case (Fig. 5a and b), although the sintered joint size was expected to increase with increasing fiber-fiber angle by the fiber-fiber sintering model. ${ }^{8}$

A further analysis of the experimental data on sintered joint size and number revealed a marked normal or Gaussian distribution in both cases (Fig. 6a). The mean values $(\mu)$ and standard deviations $(\sigma)$ are similar:

Without pre-annealing $\mu=17.5 \mu \mathrm{m} ; \sigma=5.5 \mu \mathrm{m}$. With pre-annealing $\mu=16.6 \mu \mathrm{m} ; \sigma=5.2 \mu \mathrm{m}$.
The identification of normal distribution for sintered joint size is important in that the sintered joint size will always tend to spread over a broad range, and small joints (e.g. $<6.5 \mu \mathrm{m}$ or $<\mu-2 \sigma$ ) are part of the sintering process. However, both small $(<\mu-2 \sigma)$ and large $(>\mu+2 \sigma)$ sintered joints are limited to a maximum of $2.5 \%$ each $(95 \%$ of the values are within $\mu \pm 2 \sigma$ for a normal distribution). The vast majority (95\%) are within $\mu \pm 2 \sigma$, which range from $6.5 \mu \mathrm{m}$ to $28.5 \mu \mathrm{m}$ for samples sintered without pre-annealing and from $6.2 \mu \mathrm{m}$ to $27 \mu \mathrm{m}$ for samples sintered with pre-annealing. The most important group of sintered joints can be regarded as those within $\mu \pm \sigma$, which account for $68.27 \%$ of the sintered joints. Owing to similar sintered joint size distributions with and without pre-annealing, the total number of sintered joints becomes critically important in determining the strength of sintered fiber felt (314 versus 221 in this study). Another difference observed from the sintered joint size distributions in Fig. $6 \mathrm{a}$ is that the sample sintered without pre-annealing had a consistently higher percentage of sintered joints in the size range above $\mu+\sigma$, while the sample sintered with pre-annealing had a consistently higher percentage 

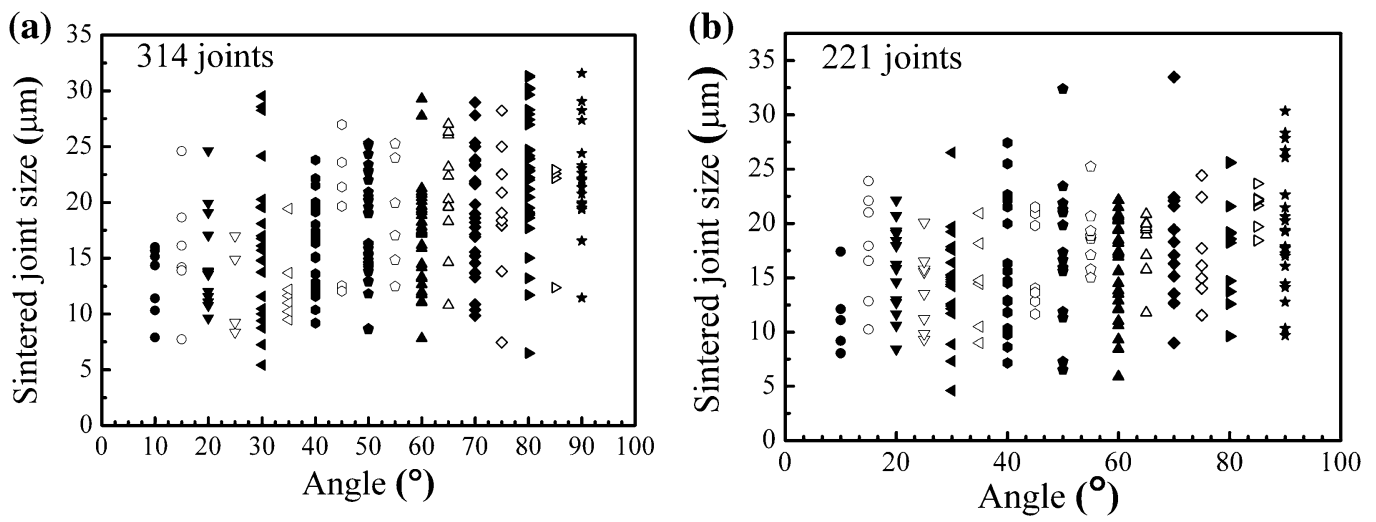

Fig. 5. Number and size of sintered joints in fiber felt samples sintered with pre-annealing at $850^{\circ} \mathrm{C}$ for 30 min (a) and without pre-annealing (b).
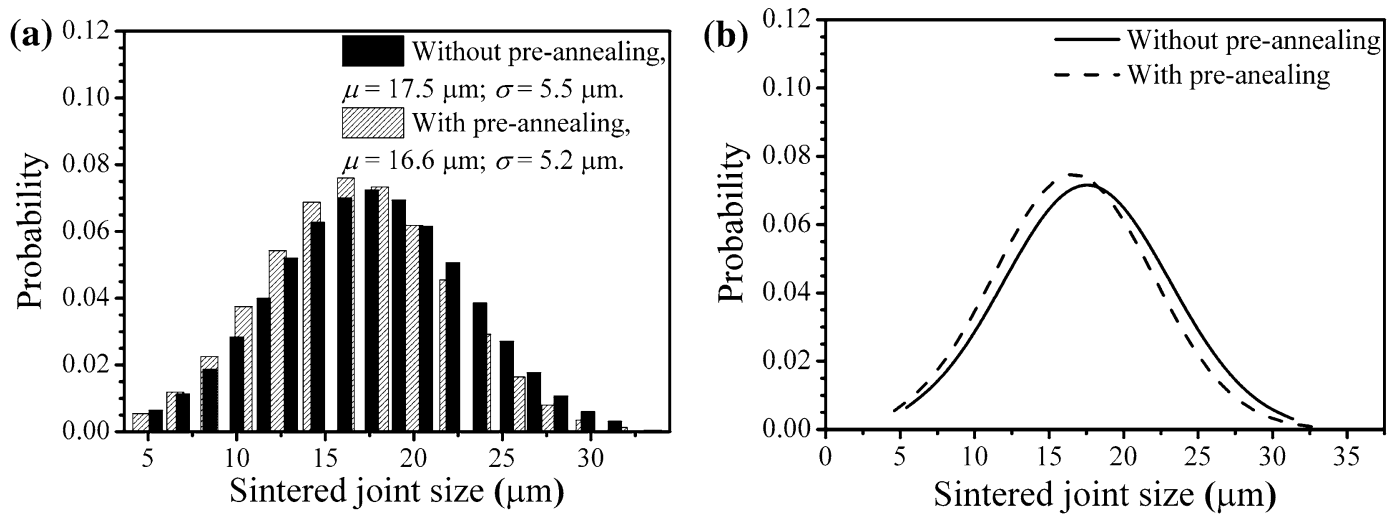

Fig. 6. (a) Distributions of sintered joint size in samples sintered with and without pre-annealing and (b) the corresponding normal distribution profiles.

of sintered joints in the size range below $\mu-\sigma$. This is best shown in Fig. 6b, which compares the two normal distribution profiles. Therefore, sintering without pre-annealing led to two important changes, a large increase (by 40\%) in the number of sintered joints and an increase in the percentage of large sintered joints $(>\mu+\sigma)$.

A detailed identification of the mechanism behind these two important changes is beyond the scope of this study, which will be investigated in the near future. However, it seems logical to attribute these positive outcomes to the following reasons:

- Owing to their high elasticity (130 GPa), asdrawn stainless steel fibers in the fiber felt preform can keep in tight contact with each other after compaction before being put in the sintering furnace. These tight contacts create an important physical basis for the subsequent formation of sintered joints during isothermal sintering.

- As-drawn fibers have a high dislocation density, which can easily activate volume diffusion between two fibers in the vicinity of their contact region in the early stages of sintering, thereby leading to the formation of healthy sintered joints (e.g., large than $17.5 \mu \mathrm{m}$, Fig. 6a). Surface diffusion is known to drive morphological evolution of long rod-like objects during isothermal holding towards either smoothening or breaking up the cylindrical surfaces. ${ }^{9,10}$ After sintering, the surface morphology of the fibers (Fig. 4b) remained very similar to that of the as-drawn fibers (see Fig. 2 in Ref. 5). This observation supports the inference that surface diffusion is limited during the 10-min isothermal sintering at $1000^{\circ} \mathrm{C}$ while the formation of large sintered joints $(>17.5 \mu \mathrm{m}$, Fig. 6a) can be mainly ascribed to dislocation-assisted volume diffusion.

\section{CONCLUSION}

The following conclusions can be drawn from this study. 
1. Distribution of the sintered joint size of samples showed a marked normal distribution with and without pre-annealing.

2. Pre-annealing before sintering led to a significant reduction $(>40 \%)$ in the number of sintered joints and an increase in the percentage of sintered joints smaller than $\mu-\sigma$ compared to without pre-annealing. Consequently, fiber felt samples sintered with pre-annealing exhibited a reduction of more than $50 \%$ in tensile strength.

3. Fiber felt samples sintered at $1000^{\circ} \mathrm{C}$ for $10 \mathrm{~min}$ with and without pre-annealing showed similar grain structures, without bamboo-like grains.

4. Fiber felt samples sintered with and without pre-annealing exhibited distinctly different modes of tensile failure. The former (with preannealing) was governed by delamination due to fracture of joints between interlayers, while the latter (without pre-annealing) was dominated by the fracture of individual fibers.

5. Sintering without pre-annealing is necessary for the fabrication of high-strength fiber felt products.

\section{ACKNOWLEDGEMENTS}

We thank the financial support received from the National Natural Science Foundation of China
(51134003), the Youth Scientific Star Project of Shaanxi Province (2014KJXX-24), and the Key Scientific and Technological Innovation Team Project of Shaanxi Province (2015KCT-11). Furthermore, the authors wish to thank the technical support of the Shanghai Synchrotron Radiation Facility (SSRF).

\section{REFERENCES}

1. J. Zhang, H.P. Tang, Z.P. Xi, and Q.B. Wang, Rare Metal Mater. Eng. 35, 438 (2006).

2. B. Zhang and T.N. Chen, Appl. Acoust. 70, 337 (2009).

3. Q.B. Ao, J.Z. Wang, H.P. Tang, H. Zhi, J. Ma, and T.F. Bao, Rare Metal Mater. Eng. 44, 2646 (2015).

4. I. Yuranov, L. Kiwi-Minsker, and A. Renken, Appl. Catal. B Environ. 43, 217 (2003).

5. J.Z. Wang, H.P. Tang, M. Qian, A.J. Li, J. Ma, Z.G. Xu, C.L. $\mathrm{Li}$, Y. Liu, and Y. Wang, JOM 68, 890 (2016).

6. J. Ma, A.J. Li, and H.P. Tang, Metals 6, 1 (2016).

7. A.J. Li, J. Ma, J.Z. Wang, Z.G. Xu, C.L. Li, and H.P. Tang, Powder Technol. 288, 109 (2016).

8. H.P. Tang and J.Z. Wang, Porous Metal Fiber Materials: Pore Structure \& Performance, 1st ed. (Beijing: Metallurgical Industry Press, 2016), pp. 91-115.

9. Q. Ma, Acta Mater. 46, 1669 (1998).

10. M. Qian, Scr. Mater. 36, 77 (1997). 